\title{
Incorporation of Human Factors into a Discrete Event Simulation Model for Human Centred Assembly Performance Evaluation
}

\author{
M. I. Abubakar ${ }^{\mathrm{a}, *}, \mathrm{Q}$. Wang ${ }^{\mathrm{b}}$ \\ ${ }^{a}$ Department of Computer Engineering, School of Engineering Technology, Binyanimu Usman Polytechnic, \\ Hadejia, Jigawa State, NIGERIA. \\ ${ }^{b}$ School of Mechanical and Design Engineering, University of Portsmouth, Portsmouth, PO1 3DJ, UK.
}

\begin{abstract}
Discrete Event Simulation (DES) tool is commonly used for the design, analysis, and evaluation of manufacturing systems. Human centred assembly systems offer better system flexibility and responsiveness due to inherent human intelligence and problem-solving abilities; human can deal with product variations and production volumes; and can always adapt themselves to multiple tasks after learning process. Nevertheless, human performance can be unpredictable, and may alter over time due to varying psychological and physiological states, these are often overlooked by researchers when designing, implementing, or evaluating a manufacturing system. In this paper a user-friendly integrated DES method was proposed to enable manufacturing system designers to investigate overall performance of human centred system considering effects of selected human factors. the method can permit manufacturing system designers to evaluate overall manufacturing system performance with considerations of parameters of human factors at early design stage. A case study was carried out using integrated approach; simulation results demonstrate the applicability of this approach.
\end{abstract}

Keywords: human performance, human centred assembly system, simulation, human factors, aging, experience

\section{INTRODUCTION}

For a human-centred assembly line, assembly tasks are often grouped and distributed to individual workers and each worker is expected to complete assigned assembly tasks within a specified cycle time. These intends to minimise inprogress idle time due to unbalanced line; maximise the utilization of workers and increases productivity. When modelling human centred assembly systems in DES we assume assembly line of workers with same performance capacity [1]. In reality, completion time of assembly tasks by human workers largely depends on variation of individual workers who may work at varying speeds, different levels of skill, and may subject to complexity of the task as well as other factors such as working conditions or environment in light, noise, temperature and so on $[2,3]$. Other factors such as: musculoskeletal injuries due to prolonged use of hands-on manual tasks, long-time pressure, repetitive wrist motion and awkward hand posture associated with the prevalence musculoskeletal disorders may have considerable effects on workers' health conditions, which may

${ }^{*}$ Corresponding author (Tel: +234(0) 901165 5439)

Email addresses: maji.abubakar@myport.ac.uk (M. I. Abubakar), qian.wang@port.ac.uk (Q. Wang) also affect worker performance [4]. Also, working under conditions of stress and fatigue and hostile physical working environment can also contribute inefficiency in assembly operations resulting to low quality outputs $[2,5]$.

Biomechanical models can be applied to understand adverse human effects on the performance of a system [6]. However, a straightforward answer in terms of an overall impact on a human centred system performance measured by such as product cycle time, throughput, utilization of individual human workers and so on cannot be provided by these models.

Human variability can be attributable to several factors including skills, physical capacity, and it affects the way tasks are executed [7]. Through a literature study, human factors related to age and experience were identified as the major source of task time variability of human workers [8,9]. In a typical DES model, assembly time cycle time a form of statistical gamma distribution is mostly used as an appropriate pattern for modelling manual tasks [10,11]. As discussed previously, the current DES tools in the market cannot be used for examining effects of human factors on human performance for a manufacturing system design and evaluation. This is because an operator in a DES model is treated as a machine pro- 
cessing product within a specified cycle time [1014].

There are some studies in a view of sociotechnical or psychological sciences to evaluate the effects of human factors or human performance relating to the design of manufacturing systems. Nevertheless, these studies are basically described in a form of general language that manufacturing engineers often find difficult to understand [15]. Bainess [12] first drew attention of missing human factors in discrete event simulation modelling, their study examines the influence of human factors on the reliability of DES results, other studies also reported in literatures $[1,10,16,17]$. Boenzi et al. [18] reported the human ageing phenomenon as critical element lacking $\mathrm{n}$ modelling simulation and analysis of manufacturing systems. Towards solving this problem Perez et al. [10] incorporates muscular fatigue and recovery pattern model in evaluating human workload at initial design stage of manufacturing system. Digiesi et al. [19] observe the significance of changing worker behavior on flow line performance using DES. Impact of human behavior on task time variation was also investigated by Mason et al. [20]. Wang et al. [1] used DES to model human learning pattern during assembly operation.

This study proposes an approach to improving the capabilities of Discrete Event Simulation, effective and user-friendly platform is created that can be integrated with DES to consider inherent human performance variations due ageing and experience. The framework can offer understanding into the trend of worker performance due to effects of aging and experience.

\section{HUMAN FACTORS FOR HUMAN CENTRED ASSEMBLY SYSTEMS}

Lassila et al. [21] emphasised the significance of individual human worker on the performance of manufacturing cell regardless of its automation level. It was reported that approximately one third of German companies invested in highly advanced automaton have recognized that these solutions were not flexible enough and have reduced their level of automation; $38 \%$ of these companies have reduced automation by taking advantage of a more efficient qualified workforce [15, 22]. Moreover, Mercedes-Benz is relying more on human workers for assembly and, Honda car maker uses robots in final assembly where workers are still employed to install motors, wheels, and trim components [23]. Assembly operations involve a process of such as gripping, picking, inserting, positioning, fastening, and checking parts, which is usually being carried out in a pre-defined assembly sequence along a production line. Assembly operations accounts for about $50 \%$ of total production time and $20 \%$ of total unit production cost [24]. For manual assembly, assembly operations are primarily performed by human workers with inherent dexterity, skills, and sense of judgment [25]. As an example, a walking worker assembly line where workers are cross trained to execute assigned assembly work by walking down the line to assemble a product from start to end. When assembly operator reaches downstream of the assembly line, he/she withdraws and travel back to the front end of the line to start with a new task. Previous studies showed that walking walker assembly lines outperform conventional fixed worker assembly lines as it offers more flexibility, efficiency, and responsiveness: the number of walking workers on the line can be adjustable in response to varying demands, also higher utilization of individual workers can be achieved even with a decrease in the overall production output. Working worker assembly line system is self-balancing, and therefore costs associated with storage buffers can be reduced or eliminated [1, 26]. Among the limitations of walking worker assembly lines is it needs multifunctional, dynamic, and cross-trained workers to perform all the required tasks efficiently, and the crosstraining level of workers may be at the expense of cost. Most importantly, the overall system performance may alter due to varying performance of individual workers who have such as different ages and experience.

\section{MATERIALS AND METHODS}

There are some studies on aging workforce in relation to manufacturing or production research [27]. Evidence showed that individual performance of workers declines from certain age due to natural decline of their physiological functions in such as visual ability, musculoskeletal force, flexibility/motion capability, memory/concentration, and thermoregulation [5, 22, 25, 28-30]. The influence of these factors on human performance can be unpredictable and it may alter due to individuals psychological and physiological: individuals cultural, social and health conditions $[11,12]$. Table 1 summarizes the findings in decline of human functional ability over the increase of age through a literature review.

\section{NOTATIONS}

The following notations are used: $T_{n}$ Time to produce $n^{\text {th }}$ unit.

$T_{n}^{I E}$ : Time to produce $n^{\text {th }}$ unit by inexperienced worker.

$T_{n}^{E}$ : Time to produce $n^{\text {th }}$ unit by experienced worker.

$F_{d l}$ : Decline rate of human performance after 38 years old.

$\triangle_{t l}^{I E}$ : Loss of time to produce $n^{t h}$ unit by inexperienced worker after 38 years old.

$\triangle_{t l}^{E}$ : Loss of time to produce $n^{t h}$ unit by experienced worker after 38 years old.

${ }^{I E}$ : Average assembly time to produce $n^{\text {th }}$ unit by inexperienced worker after 38 years old.

$\tau^{E}$ : Average assembly time to produce $n^{\text {th }}$ unit by experienced worker after 38 years old.

$I E$ : Inexperienced assembly operator.

$H E O$ : Highly experienced.

$E O$ : Experience 
Table 1: Decline of human functional abilities vs aging.

\begin{tabular}{|c|c|c|c|}
\hline Ability & Functions & Performance variations & Authors \\
\hline \multirow{4}{*}{ Endurance } & \multirow{4}{*}{ Aerobic capacity } & Peak at the age of 40 and decline by $1 \%$ per year after. & [28] \\
\hline & & Peak at the age of 30 & {$[31,32]$} \\
\hline & & and decline by $0.5-1.5 \%$ per year & \\
\hline & & Decline by $1-1.5 \%$ & [33] \\
\hline \multirow{10}{*}{ Psychomotor } & \multirow{10}{*}{ Spatial ability } & Decline by $1 \%$ & [34] \\
\hline & & Decrease by $1 \%$ & [35] \\
\hline & & per year after the age of 35 & \\
\hline & & Peak at the age of 30 & [36] \\
\hline & & and decline at $1 \%$ per year after. & ת \\
\hline & & $\begin{array}{l}\text { Peak at the age of } 40 \text { and decline } \\
\text { between } 0.8 \text { and } 1.0 \% \text { per year after. }\end{array}$ & [37] \\
\hline & & Peak at the age of 30 , decline & {$[38,39]$} \\
\hline & & $\begin{array}{l}\text { by } 0.5 \% \text { per year up to the age } \\
\text { of } 40 \text { and then decline by }\end{array}$ & \\
\hline & & $1 \%$ every year up to the age of 65 & \\
\hline & & $\begin{array}{l}\text { Peak at the age of } 45 \text { and } \\
\text { decline by } 1-1.5 \% \text { per year after. }\end{array}$ & [40] \\
\hline \multirow[b]{2}{*}{ Awkward posture } & \multirow[b]{2}{*}{ Flexibility } & $\begin{array}{l}\text { Peak at the age of } 40 \text { and } \\
\text { decline by } 0.8-1 \% \text { per vear after. }\end{array}$ & [41] \\
\hline & & Peak at the age of 35 and decrease & [42] \\
\hline Overall performance & Physiological function & $\begin{array}{l}\text { at about } 1.0 \% \text { per year trom } 35 \text { to } 54 \\
\text { Peak at } \\
\text { the age of } 35-40 \text { and decline } \\
\text { by } 1 \% \text { per year after. }\end{array}$ & {$[40,43,44]$} \\
\hline
\end{tabular}

IEO: Inexperienced.

$Q$ : Incompressible factor (constant), taken approximately as 0.25 .

$N$ : $n^{\text {th }}$ unit.

$G$ : Number of times similar operation is performed by an assembly operator.

$D$ : Maximum number of assembly units.

$k_{1}$ : Existing age in years.

$F_{r m}$ Remaining human capacity in percentage after 38 years old.

$k_{2}$ : 38 years old full human capacity.

$L_{r}$ : Human capacity loss rate (in percentage) per year.

$L E_{r}$ : lost rate of human functional capacity $(\%)$ at any given period after the age of 38 years old.

$T_{\max }$ : Assigned time to assemble first unit.

$p^{n}:$ Factor of significance.

$R$ : Learning index.

From Table 1, scholars have divergent views on the stage at which human functional capacity is full, literature suggests that it ranges from 30 to 40 years. Taking average of these values, it is assumed as 38 years for this study; from Table 1 Robertson and Tracy [28] concluded that the ability of humans to do sustained heavy work reaches their peak at the age of 40 years old and decline by $1 \%$ per year afterward. Ellis et al. [36] suggests that human ability to remember and make judgements approaches its peak at age of 30 and subsequently decline by $1 \%$ every year. Asogwa [43], Ilmarinen [44], and Savinainen [32] suggested that overall human performance in terms of their physiological abilities peak at age of between 30 and 45 and decline by $1 \%$ thereafter. Thus, the age of 37.5 years is considered as an average for their studies. Table 2 shows human abilities (such as aerobic, spatial, flexibility and physiological abilities) against varying age extracted from Table 1.

From the study shown in Table ??, a regression analysis obtained by plotting age and capacity decline using Minitab software analysis tool, the rate of ability/capacity decline shows a strong positive correlation with age. Thus, the regression equation is given as:

$$
L_{r}=0.57+0.012 k_{1}
$$

The lost rate of human functional capacity $(\%)$ at any given period after the age of 38 years old can be evaluated as:

$$
L E_{r}=\left(0.57+0.012 k_{1}\right)\left(k_{1}-k_{2}\right)
$$

The human functional capacity decline rate (\%) after 38 years old is denoted as:

$$
\begin{aligned}
F_{d l}= & {\left[100-\left(0.57+0.012 k_{1}\right)\left(k_{1}-k_{2}\right)\right] } \\
& {\left[100-\left(0.57+0.012 k_{1}\right)\left(k_{1}-k_{2}\right)\right] } \\
& {\left[100-L E_{r}\right] }
\end{aligned}
$$

Table 3 shows human capacity rate (\%) over age using Eqs. (1) and (3) respectively.

In this case study, experience is defined as knowledge or skills gained through involvement of a specific assembly task. In a human centred assembly line, for instance, experience can be quantified as a learning curve that refers to trend in the reduction of assembly time over an increase of assigned assembly tasks [45]. Thus, it is expressed in Eq. (4) with the parameter $Q(0 \leq Q \leq$ 1 ), where if $Q=$ zero it indicates a task that is 
Table 2: Human abilities vs ages based on literature.

\begin{tabular}{llll}
\hline Ability/capacity & Peak (years) & Rate of Ability/capacity decline & Study \\
\hline Psychomotor & 45 & 1.25 & {$[40]$} \\
Endurance & 40 & 1.0 & {$[28,37]$} \\
Psychomotor & 40 & 0.9 & {$[41]$} \\
Overall performance & 37.5 & 1.0 & {$[32,43,44]$} \\
Awkward posture & 35 & 1.0 & {$[42]$} \\
Endurance & 30 & 1.0 & {$[31,32,34]$} \\
\hline
\end{tabular}

Table 3: Human functional capacity (\%) vs age.

\begin{tabular}{|c|c|c|c|}
\hline Age & $\begin{array}{l}\text { Loss rate of human } \\
\text { capacity }(\%) \mathbf{L}_{\mathbf{r}}\end{array}$ & $\begin{array}{l}\text { Human functional capacity } \\
\text { decline rate }(\%) L E_{r}\end{array}$ & $\begin{array}{c}\text { Remaining human Functional capacity } \\
(\%) \text { after the age of } 38\left(F_{\mathrm{dl}}\right)\end{array}$ \\
\hline 38 & 0 & 0 & 100 \\
\hline 40 & 1.05 & 2.10 & 97.9 \\
\hline 45 & 1.11 & 7.65 & 92.35 \\
\hline 50 & 1.17 & 13.50 & 86.50 \\
\hline 55 & 1.23 & 19.65 & 80.35 \\
\hline 60 & 1.29 & 26.10 & 73.90 \\
\hline 65 & 1.35 & 32.85 & 67.15 \\
\hline 70 & 1.41 & 39.90 & 60.10 \\
\hline 75 & 1.47 & 47.25 & 52.75 \\
\hline 80 & 1.53 & 54.90 & 45.10 \\
\hline
\end{tabular}

manually performed; and if $Q=$ one it indicates a task that is predominantly executed by machines. Hence, time to produce unit is given by:

$$
T_{n}=\left[\left(Q+(1-Q) N^{R}\right)\right] T_{\max }
$$

The difference between experienced and highly experienced is measured by times same operations is performed by an assembly worker. Therefore, average time to produce $n^{\text {th }}$ unit by a highly experienced worker at full capacity is given in Eq. (5) as:

$$
T_{n}^{E}=\left[\left(Q+(1-Q) G^{R}\right)\right] T_{\max }
$$

where $G$ refers to times the same operations is performed by an assembly worker. Thus, average time to produce $n^{\text {th }}$ unit by an inexperienced worker at full capacity is given as:

$$
T_{n}^{I E}=\left[\left(Q+(1-Q) N^{R}\right)\right] T_{\max }
$$

where $N$ is $n^{t h}$ unit.

Since experience is determined in this study as the time an operation is repeatedly performed relevant task by assembly, therefore Eq. (7) represents loss of assembly time by experienced worker due to aging:

$$
\triangle_{t l}^{E}=F_{d l} \times T_{n}^{E}
$$

Thus,

$$
\begin{aligned}
\tau_{t l}^{E}= & {\left[\left(L_{r}\left(\left(k_{1}+k_{2}\right)+L E_{r}\right) \times 0.01\right]\right.} \\
& \times\left[\left(Q+(1-Q) G^{R}\right)\right] T_{\max }
\end{aligned}
$$

By considering Eq. (5), average assembly time to produce an assembly unit by highly experience and experienced worker after full performance capacity (age of 38 years old) is expressed as:

$$
\tau_{n}^{E}=\triangle_{t l}^{E}+T_{n}^{E}
$$

$$
\begin{aligned}
\tau_{n}^{E}= & {\left[\left(L_{r}\left(\left(k_{1}+k_{2}\right)+L E_{r}\right) \times 0.01\right]\right.} \\
& \times\left[\left(Q+(1-Q) G^{R}\right) T_{\max }\right] \\
& +\left[Q+(1-Q) T_{\max }\right]
\end{aligned}
$$

Loss of assembly time to produce $n^{\text {th }}$ unit by inexperience worker after full performance capacity (age of 38 years old) is given in as:

$$
\triangle_{t l}^{E}=F_{d l} \times T_{n}^{I E}
$$

$$
\begin{aligned}
\tau_{n}^{I E}= & {\left[\left(L_{r}\left(\left(k_{1}+k_{2}\right)+L E_{r}\right) \times 0.01\right]\right.} \\
& \times\left[\left(Q+(1-Q) N^{R}\right) T_{\max }\right]
\end{aligned}
$$

By considering Eq. (6), average assembly time by an inexperienced worker due to aging is taken as:

$$
\begin{aligned}
\tau_{n}^{I E}= & {\left[\left(L_{r}\left(\left(k_{1}+k_{2}\right)+L E_{r}\right) \times 0.01\right]\right.} \\
& \times\left[\left(Q+(1-Q) N^{R}\right) T_{\max }\right] \\
& +\left[Q+(1-Q) T_{\max }\right]
\end{aligned}
$$

\subsection{Integrating Aging and Job Experience into a DES Model}

Figure 1 shows AutoHmot graphical user interface developed in the Java-based JBuilder tool. Figure 2 shows data obtained from AutoHmot, it indicates assembly time of a worker (at full capacity of 38 years old) declines over the increasing 


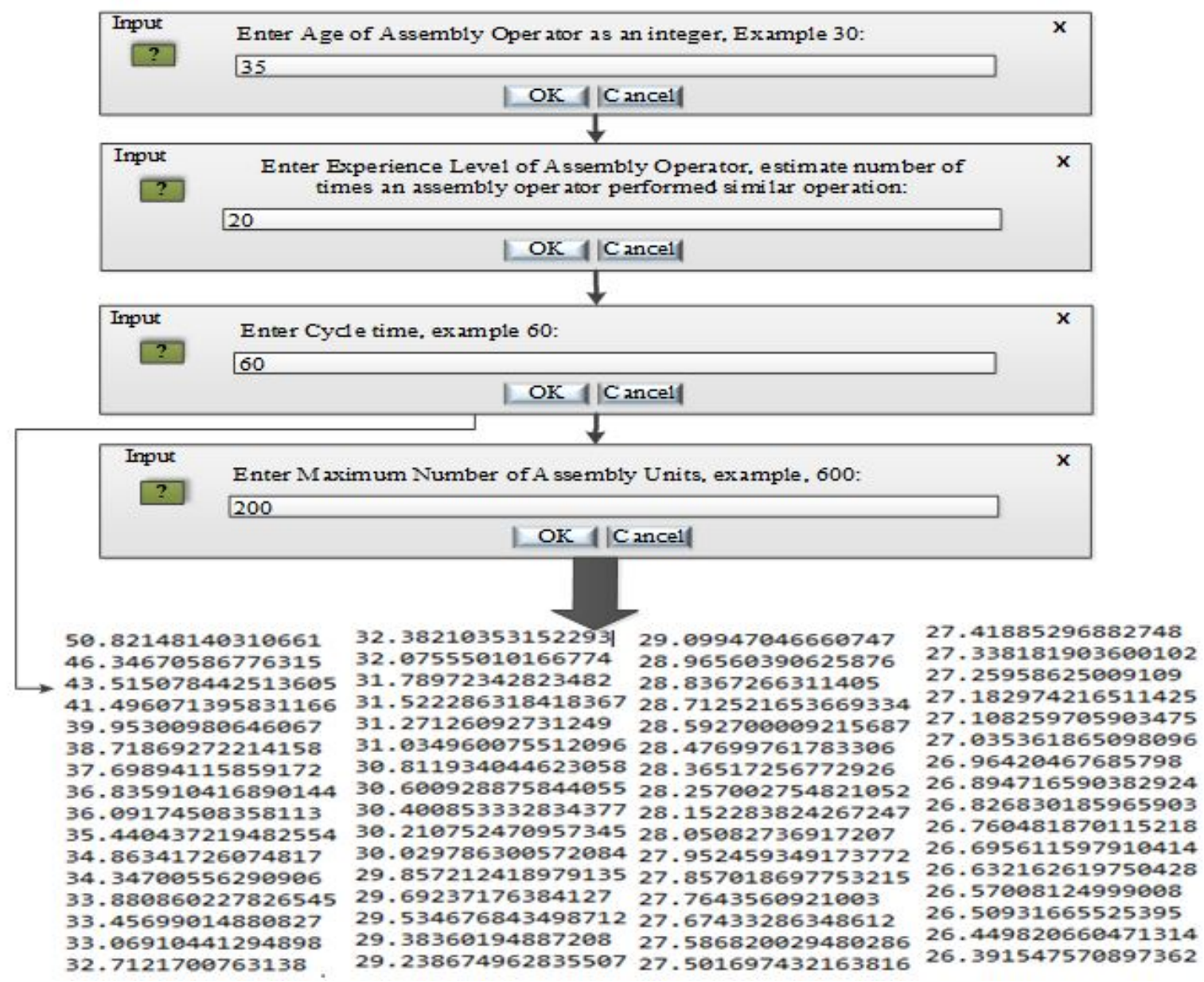

Figure 1: AutoHmot user interface and solutions.

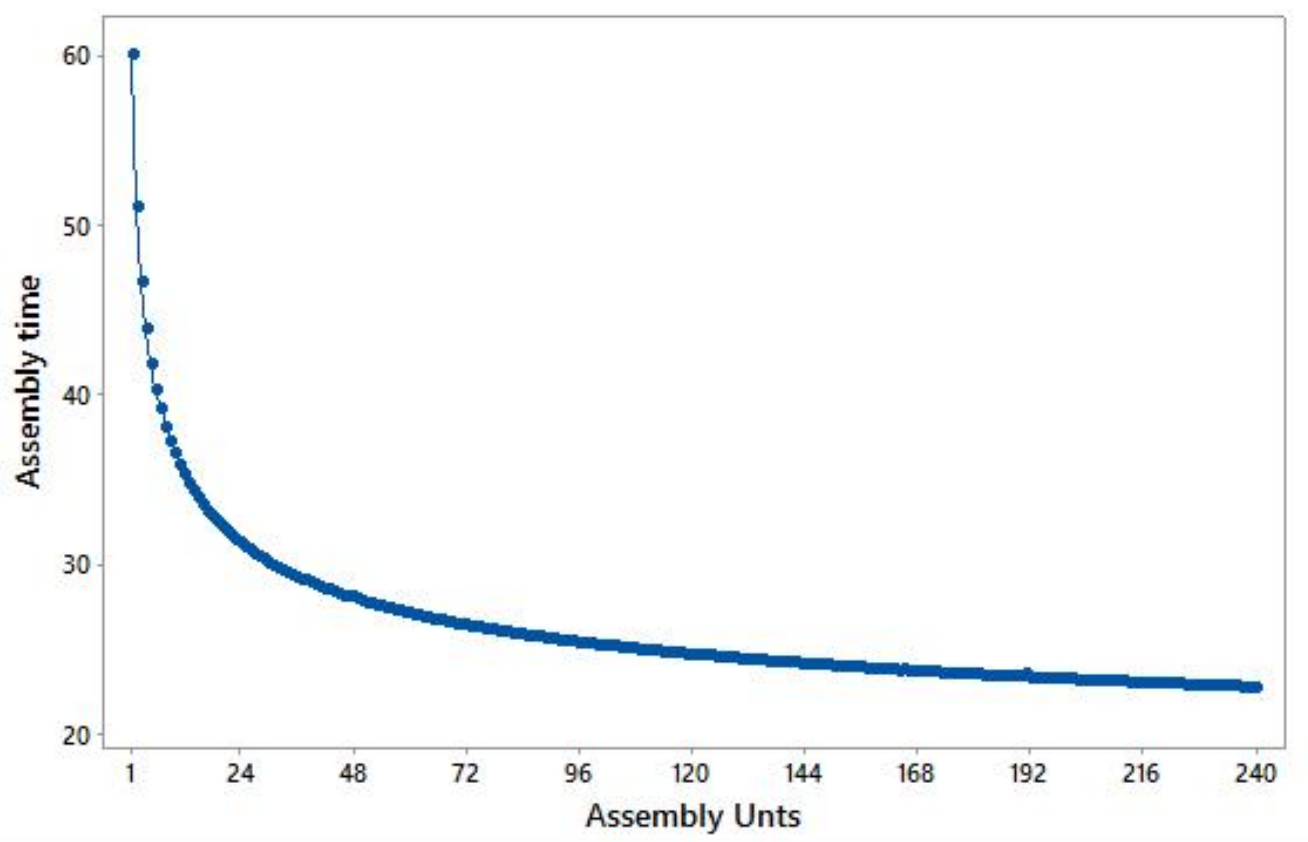

Figure 2: Assembly time vs assembly units completed by a worker at full capacity of 38 years old. 
number of assembled units during learning process [9]

Figure 3 illustrates the mechanism of the integrated DES model interfaced with AutoHmot. Once relevant data are collected and entered $\mathrm{Au}$ toHmot by user AutoHmot compute the assembly time. One of the benefits of AuttoHmot is that it requires minimum input from user. The data required from AutoHmot include existing age of an assembly worker; experience level or number of tasks performed by an assembly worker; cycle time assigned to assemble a unit; and total number of assembly units that need to be completed during process.

\subsection{Desirability Function Analysis (DFA)}

Optimization of product and/or processes is often a common practice in the manufacturing industry: characteristics of interest; products or processes are evaluated by a number of performance measures or responses against their relative importance or value. Desirability criterion is among multi-objective-optimization technique that transforms responses into individual desirability functions, a value bounded between 0 and 1 , an increase from 0 makes the corresponding response value more desirable, it is further aggregated into either a geometric or arithmetic mean. The rationale behind desirability functions is that the composite or overall desirability function obtained from an experiment is not desirable if one of the quantities measured is out of the desired boundary [46]. The sensitivity of the DFA technique has been demonstrated by Costa, Lourenço, and Pereira [46]; Costa and Lourenço [47]; Âlzuheri [48], and Jr. and Simpson [49]. Different types of desirability function are suggested in literature [46, 47], Desirability function combined corresponding response values into weighted geometric mean represented by $D_{f}$ as follows:

$$
D_{f}=\left[\prod_{n=1}^{n} d_{i}^{r^{n}}\right]^{\frac{1}{\Sigma p^{n}}}
$$

where: $p^{n}$ is a factor of significance, which is assigned subjectively indicating the importance of each performance measure; $d_{i}(i=1, \ldots n)$ is the individual desirability corresponding to each performance measure; $r^{n}$ : weight on the $i^{t h}$ response.

The methodology by Derringer and Suich (1980) provides individual desirability function based on three response types:

\section{- Nominal-The-Best (NTB)}

Representing a situation where the estimated response is planned to carry out a particular target value $T$. The individual desirability function for this response type is described as:

$$
d(x)=\left\{\begin{array}{lll}
\left(\frac{\hat{y}-L}{T-L}\right)^{P_{n}}, & & L \leq \hat{y} \leq T \\
\left(\frac{\hat{y}-U}{T-L}\right)^{t}, & & L \leq \hat{y} \leq T \\
0 & \rightarrow & \text { Otherwise }
\end{array}\right.
$$

- Larger-The-Best (LTB):

A situation where the value of the estimated response is intended to be larger than a lower limit. For this category of response, the individual desirability function is defined as:

$$
d(x)=\left\{\begin{array}{l}
0 \\
\left(\frac{\hat{y}-L}{T-L}\right)^{P_{n}}, \quad L \leq \hat{y} \leq T \\
1
\end{array}\right.
$$

- Smaller-The-Best (STB):

The value of the estimated response is expected to be smaller than an upper limit. For this response type, the individual desirability function is defined as:

$$
d(x)=\left\{\begin{array}{l}
1 \\
\left(\frac{\hat{y}-U}{T-U}\right)^{P_{n}}, \quad L \leq \hat{y} \leq T \\
0
\end{array}\right.
$$

where the $L$ represents a lower tolerance limit of $\bar{y}$, the $U$ represents an upper tolerance limit of $\bar{y}$, and $p^{n}$ represents weight.

Desirability criteria involve three steps:

I. Calculating the individual desirability index for the corresponding responses using three forms of the desirability functions according to the response characteristics in Eqs. (15) to (16). The desirability value that equals to 0 represents the worst-case situation.

II. Computing composite desirability $D_{f}$ : The individual desirability index of all the responses can be combined to form a single value called composite desirability by Eq. (14).

III. Determining the preferred assembly design alternatives: The higher the composite desirability value implies a better design alternative. Therefore, based on the composite desirability $D_{f}$, the effects of worker age and experience for each design alternative is estimated and the best-preferred solution is selected.

The two performance measures used in this study are throughput and total assembly time. These performance measures are evaluated based on desirability criteria involving three steps as follows:

\section{Step 1:}

Total assembly time retains the minimization objective, while throughput aims to the maximization objective. Therefore, according to Eqs. (16) and (17), the individual desirability function for throughput and total assembly time respectively, are given as follows:

$$
d(\alpha)=\left\{\begin{array}{l}
0 \\
\left(\frac{\alpha-U}{T-U}\right)^{P_{n}}, \quad L \leq \alpha \leq T \\
1
\end{array}\right.
$$




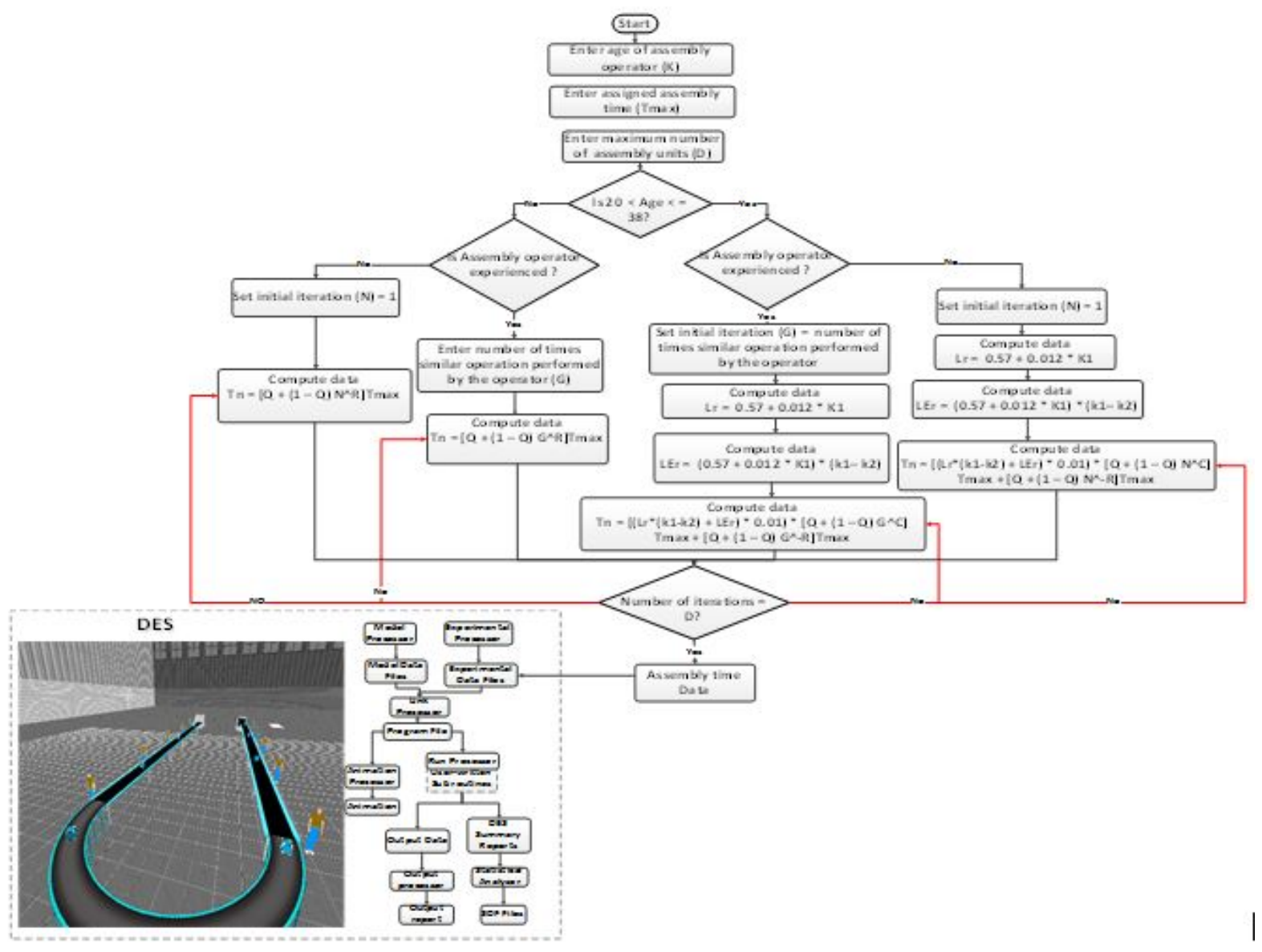

Figure 3: Integrating AutoHmot with a DES (ED) model.

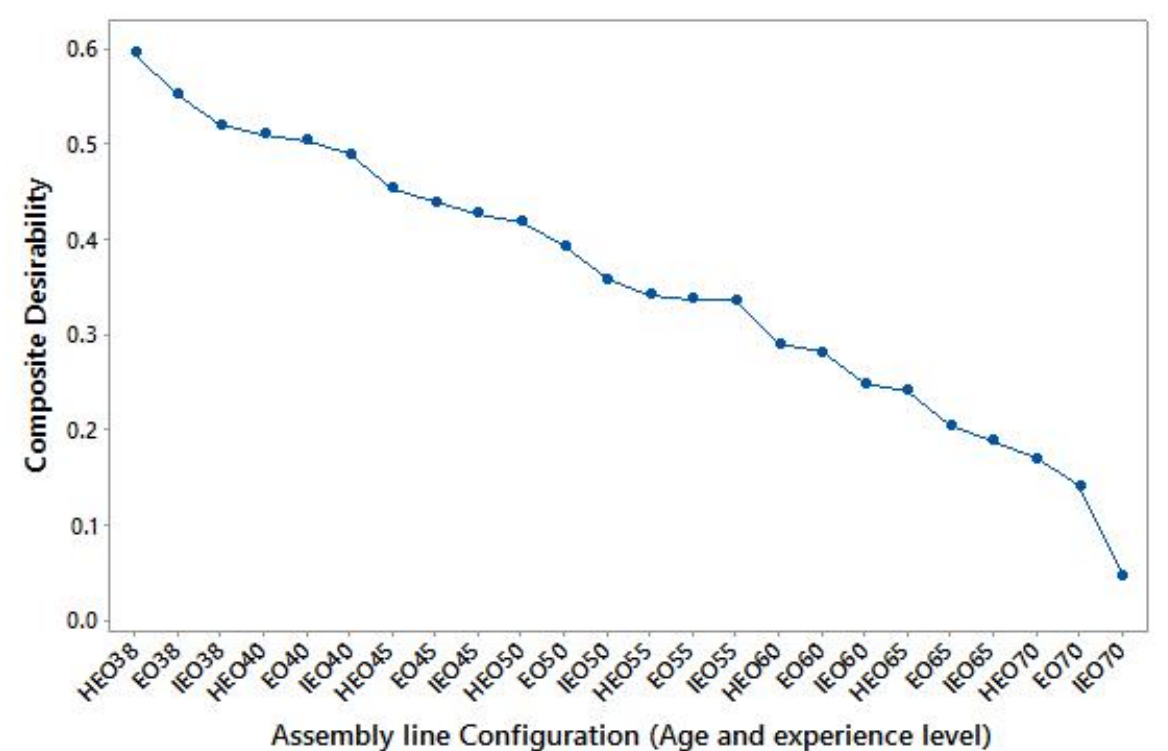

Figure 4: Trend of the composite desirability of workers based on the overall assembly line conditions. 
For throughput $\alpha$

$$
d(\alpha)=\left\{\begin{array}{l}
1 \\
\left(\frac{\delta-U}{T-U}\right)^{P_{n}}, \quad L \leq \delta \leq T \\
0
\end{array}\right.
$$

For the total assembly time.

To wider the capability of searching for worst solutions, this study follows the work of Al-zuheri [48] and Jr. and Simpson [49] by introducing the penalty function into the Derringer's desirability model: penalty function is a smaller constant added to a data, which is a common procedure used in statistics, although it introduces small error to results [49], however the introduced error may not have significant impact on the overall solution [48]. In this study a constant $\varepsilon$ as penalty function with a value of 0.001 is used to prevent the individual desirability value equalling to zero. Hence, Eqs. (18) and (19) is given by:

$$
\begin{aligned}
& d(\alpha)=\left\{\begin{array}{l}
0 \\
\left(\frac{\alpha-U}{T-U}\right)^{P_{n}}+\varepsilon, \quad L \leq \alpha \leq T \\
1
\end{array}\right. \\
& d(\delta)=\left\{\begin{array}{l}
0 \\
\left(\frac{\delta-U}{T-U}\right)^{P_{n}}+\varepsilon, \quad L \leq \delta \leq T \\
1
\end{array}\right.
\end{aligned}
$$

where $\varepsilon=0.001$ Using Eqs. (20) and (21) individual desirability $d_{i}$ and composite desirability values $D_{f}$ for each design alternative is calculated respectively. The composite desirability:

$$
\begin{gathered}
D_{f}=\left[\prod_{n=1}^{n} d_{i}^{r^{n}}\right]^{\frac{1}{\Sigma p^{n}}} \\
D_{f}=\left[d_{i}(\alpha) \times d_{i}(\delta)\right]^{\frac{1}{\sum^{n}}}
\end{gathered}
$$

where $U$ and $L$ denote upper and lower limits of the two performance measures. While $p^{n}$ denotes weight signifying importance for each response, which is assigned subjectively to each performance measure. In this case study, equal weight is assigned to all responses. Each design alternative consists of six workers having two performance measures responses, the two performance measures are assumed equal importance. In this case, the number of performance measures multiply by six workers gives the value $p^{n}$ as 12 .

A hypothetical assembly line producing single products' family was developed using Enterprise Dynamics (ED) simulation package. The assembly line consists of six stations manned by six workers. The assembly line operates four hours 30 minutes per day with fifteen minutes break inbetween shift with monthly demand requirement of 6000 units. Assuming 25 operating days per month, a daily demand of 240 units and 240 minutes (excluding 30 minutes for break) of production time gives 1 minutes of cycle time. Each assembly workstation is manned by an assembly operator with the assumed same age and experience level. Human performance in manufacturing system is measure in terms of the rate at which a task is completed, number of times a task is completed or the reliability with which a task is completed [50]. In this study experience of a worker is described as the cumulative number of similar tasks previously performed by the worker, and it is categorised into three levels: inexperienced operator (IEO); experience operator (EO): who has produced more than 20 units; and highly experience operator (HEO): who has produced more than 40 units. Worker's age is assumed to start from the age of 20 years old. A cycle time of 1 minute is assigned for the first assembly unit to be assembled, experience level of workers is also entered into the developed tool (AutoHmot). Data from AutoHmot are linked to simulation tool through excel spreadsheet. Two performance measures: throughput and total assembly time for each assembly worker is observed. Although each workstation is configured to consists of workers with same age group and experience level. The objective of the experiment is determining how ageing and experience may affects the overall performance of the assembly line. It aims to maximise throughput and minimise assembly time, which is determined by using multi-objective optimization technique; the desirability function analysis (DFA). DFA involves a transformation of response variables, in this case throughput and total assembly time, into a single value called composite desirability. Figure 4 depicts the trend by computing the composite desirability of each performance measure on different assembly line configurations.

\section{RESULTS AND DISCUSSION}

Composite desirability which measures the decline of performance indicators (throughput and total assembly times) was used to evaluate worker efficiency: time to accomplish an assigned task and quantity of units produced. 24 assembly line configurations were studied and the significance of each of the configuration based on the composite desirability is observed. The trend of the composite desirability is showed in Fig. 4. Assembly line condition 1 consist of six highly experience workers of age group 38-year, condition 2 entails six workstation with experienced workers of age group 38-years, while condition 3 comprise six inexperienced workers of same age group (38years). This scenario is observed up to age group of 80 years. The results suggest that highly experienced workers at younger age are likely to be efficient in contrast to older unskilled workers. Figure 5 reveals further the trend in the decline of the performance indicators measured using composite desirability at various levels of experience over the increase of age after 38 years old at which the human functional capacity reaches the maximum rate.

The trends of the percentage decline of the composite desirability for individual worker representing various aging groups is showed in Fig. 6 . 


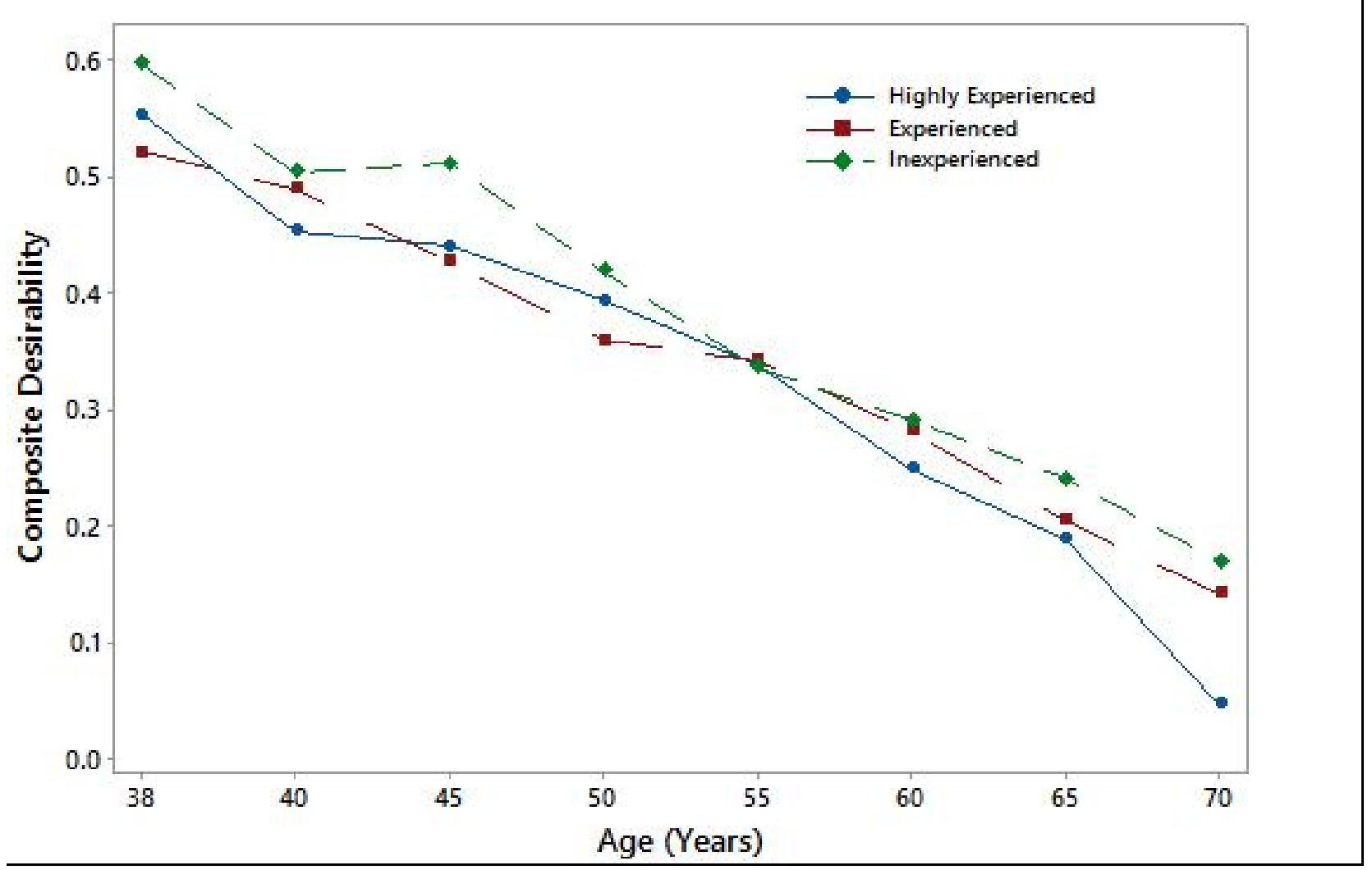

Figure 5: Trend of the composite desirability vs age.

Figure 6(a) shows the trend of the performance indicators measured using composite desirability at inexperienced level, it reveals decline of $0.14 \%$ decline for aging group 38-45 years old, $0.18 \%$ for aging group $45-50$ years old, and $0.19 \%$ for aging group 50-55 years old, respectively. It then declines to $0.13 \%$ for aging group 55-60 years old, then increase to $0.29 \%$ at aging group $65-70$ years old. It shows least decline of composite desirability at aging group 50-55 years old. These results indicate due to effects of aging the performance of inexperience worker may continue to decline from the age of 38 years old until they reach 55 years old. After this age accumulation of experience may tend to offset the decline until they reach 65 years old.

Through literature study human traits or attributes have significant impacts on manufacturing performance particularly human centred assembly systems where humans play a critical role. However, the influence of these factors is often under/overestimated or simply unnoticed in manufacturing systems design, evaluation, and analysis. Established DES tools disregard human strength and limitations. There have being poverty in research work towards the effort of considering human elements in DES environment tools. Although there were some investigations into human factors relating to human performance, there were few studies by examining the significance of critical human factors on discrete event simulation outcomes for human- centred assembly systems evaluations. In this study, the effects of experience and ageing on worker performance were examined by incorporating their parameters into a DES tool, which was used for modelling a linear human centred assembly line operated by workers under varying ages and experience as specified in a case study. With this method, the performance of each worker at the different ages is quantified.

\section{CONCLUSION}

To accurately evaluate human performance in DES tool environment factors that can be detrimental or beneficial to human performance needs to be considered. An effective and user-friendly platform is developed using the Java language to interact with parameters of physical elements (built in the DES tool) of a human centred assembly system, together with logical interrelationship for operational activities, this can enable incorporating key human factors into a DES (ED) model. Thus, this method can permit manufacturing system designers to evaluate the overall performance of a manufacturing system with considerations of parameters of human factors at early design stage. A case study was carried out using integrated approach; simulation results demonstrate the applicability of this method in assessing the influence of human factors on the overall system performance. Although two critical factors of aging and experience are considered in this study, the capability of discrete event simulation tool 


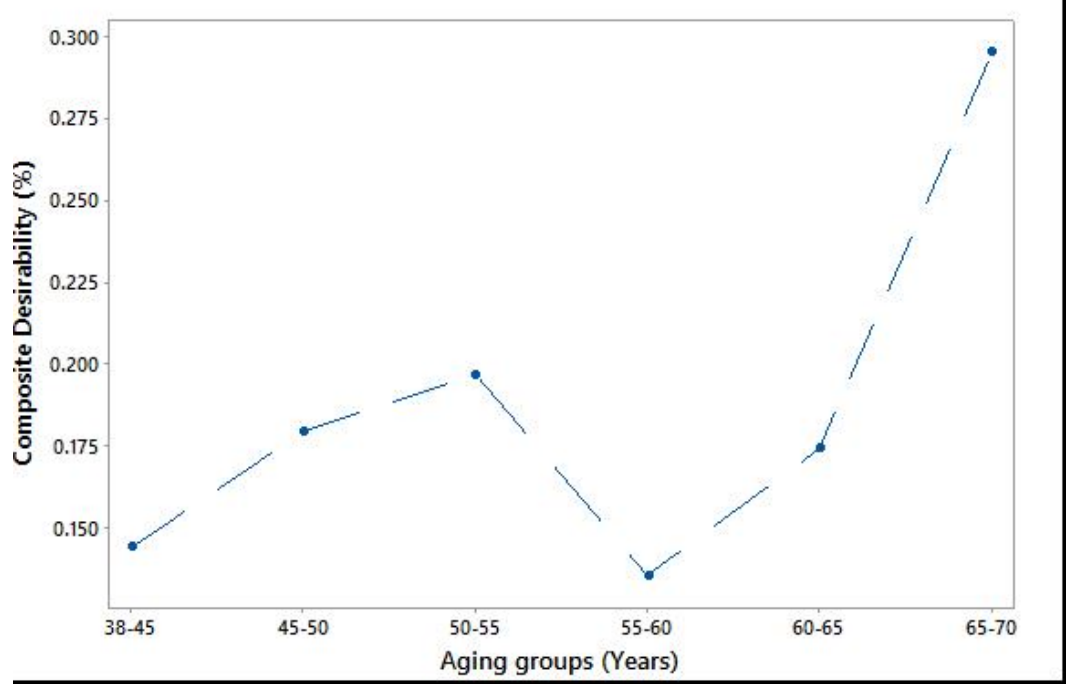

(a) Inexperienced workers.

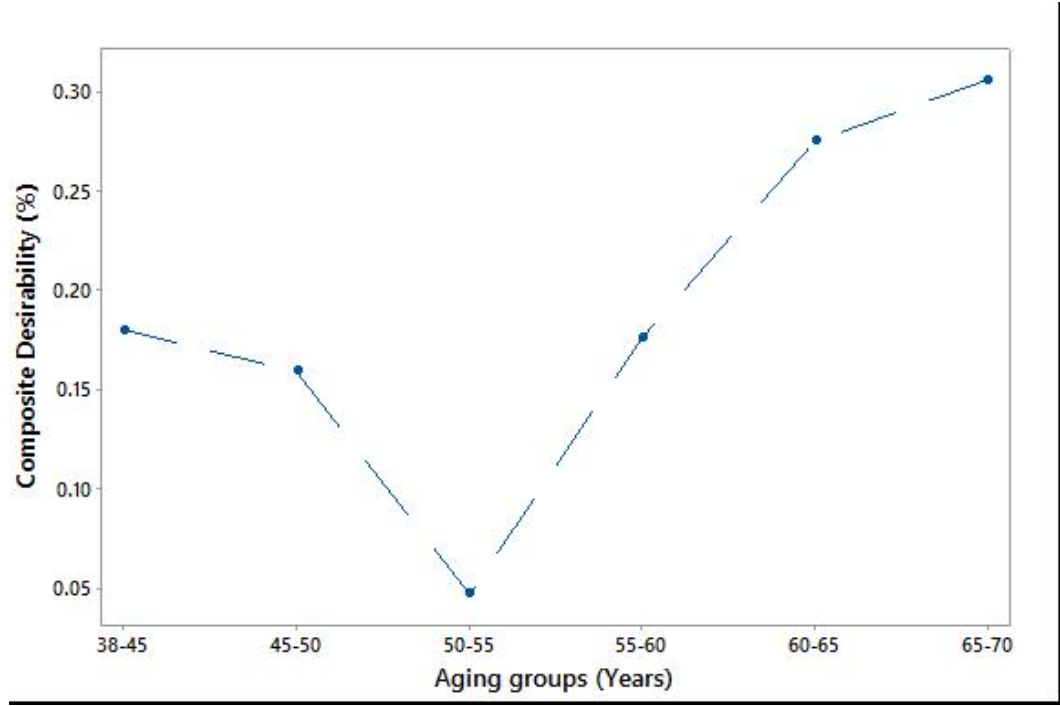

(b) Experienced workers.

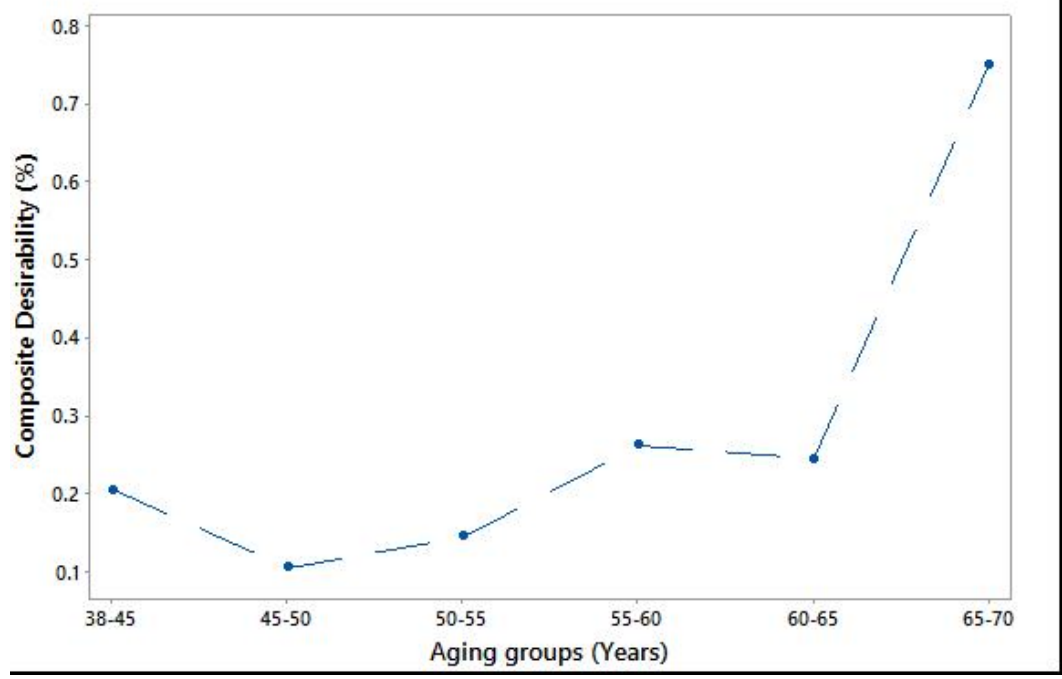

(c) Highly experienced

Figure 6: (a) Inexperienced, (b) experienced and (c) highly workers. 
can be enhanced further by integrating other elements such as psychological and psychosocial factors.

\section{References}

[1] Q. Wang, M. Sowden, and A. Mileham, "Modelling human performance within an automotive engine assembly line," International Journal of Advanced Manufacturing Technology, vol. 68, no. 1, pp. 141-148, 2013.

[2] A. Sobhani, M. Wahab, and M. Jaber, "The effect of working environment aspects on a vendor-buyer inventory model," International Journal of Production Economics, vol. 208, pp. 171-183, 2019.

[3] B. Carnahan, B. Norman, and M. Redfern, "Incorporating physical demand into assembly line balancing," IIE Transactions, vol. 33, pp. 875-887, 2001.

[4] D. Chaffin, Occupational Biomechanics, 4th ed. New Jersey: John Wiley, 2006.

[5] A. Falck and R. Rosengvist, "Relationship between complexity in manual assembly, ergonomics and assembly quality," in ergonomics for sustainability and growth, Stockholm, 2012b, pp. 19-22.

[6] C. Glock, E. Grosse, T. Kim, W. Neumann, and A. Sobhani, "An integrated cost and worker fatigue evaluation model of a packaging process," International Journal of Production Economics, vol. 207, pp. 107-124, 2019.

[7] K. Doerr and A. Arreola-ri, "A worker-based approach for modelling variability in task completion times," IIE Transactions, vol. 32, no. 7, pp. 625-636, 2000.

[8] M. Abubakar and W. Qian, "Key human factors and their effects on human centered assembly systems," International Journal of Industrial Ergonomics, vol. 69, pp. 48-57, 2019a

[9] M. Abubakar and Q. Wang, "Incorporating learning and aging attributes of workers into a des model," in International Conference on Robotics and Automation Sciences. Wuyan: IEEE, 2018b, pp. 160-163.

[10] J. Perez, M. Looze, T. Bosch, and W. Neumann, "Discrete event simulation as an ergonomic tool to predict workload exposures during systems design," International Journal of Industrial Ergonomics, vol. 44, pp. 298-306, 2014.

[11] W. Neumann and P. Medbo, "Simulating operator learning during production ramp-up in parallel vs. serial flow production," International Journal of Production Research, vol. 55, no. 3, pp. 845-857, 2017.

[12] T. Bainess, S. Mason, P. Siebers, and J. Ladbrook, "Humans: The missing link in manufacturing simulation?" Simulation Modelling Practice and Theory, vol. 12, pp. $515-526,2004$

[13] Q. Wang and C. Chatwin, "Key issues and developments in modelling and simulation-based technologies for manufacturing system analysis, design and performance evaluation," International Journal of Advanced Manufacturing Technology, vol. 25, pp. 1254-1265, 2005.

[14] A. Greasley and C. Owen, "Modelling people's behaviour using discrete-event simulation: A review" In ternational Journal of Operations and Production Management, vol. 38, no. 5, pp. 1228-1244, 2018.

[15] Q. Wang, N. Reda, and M. Abubakar, "Integrating missing parameters into A DES tool," in IOP Conference series: Materials Science and Engineering, vol. 436, no. 1. IOP Publishing, 2018, p. 012016.

[16] P. Medbo and W. Neumann, "Integrating human factors into discrete event simulations of parallel flow strategies," Production planning and control, vol. 20, no. 1 , pp. 3-16, 2009

[17] P. Dode, M. Greig, S. Zolfaghari, and W. Neumann, "Integrating human factors into discrete event simulation A proactive approach to simultaneously design for system performance and employees' well-being," International Journal of Production Research, vol. 54, no. 10, pp. 3105-3117, 2016.

[18] F. Boenzi, G. Mossa, G. Munmolo, and V. Romano, "Work aging in production systems: modelling and performance evaluation," in 25th DAAAM International Symposium on Intelligent Manufacturing and Automation. Bari, Italy: Elsevier, 2015, pp. 1108-1115.
[19] S. Digiesi, A. Kock, G. Mummolo, and J. Rooda, "The effect of dynamic worker behaviour on flow line performance," International Journal of Production Economics, vol. 120 , no. 2 , pp. 368-377, 2009.

[20] S. Mason, T. Baines, K. John, and J. Ladbrook, "Improving the design process for factories: Modelling human performance variation," Journal of Manufacturing systems, vol. 24, no. 1, pp. 44-54, 2005 .

[21] A. Lassila, S. Saad, and T. Perera, "Modelling and simulation of human - centred assembly systems - a real case study," in Emerging Solutions for Future Manufacturing System, 2005, pp. 405-412.

[22] M. Peruzzini and M. Pellicciari, "A framework to design a human-centred adaptive manufacturing system," Advanced Engineering Informatics, pp. 1-20, 2017.

[23] J. Lippert. (2018, January) Automotive news. [Online]. Available: https://www. autonews.com/article/20180123/OEM01/180129910/ why-assembly-plants-need-people-more-than-robots

[24] S. Samy and H. Elmaraghy, "A model for measuring product assembly complexity," International Journal of Integrated Manufacturing, vol. 23, no. 11, pp. 10151027,2010

[25] A. Schnbo and S. Stock, "Cognition in manual assembly," Ki-kunstiche intelligenz, vol. 24, no. 4, pp. 305-309, 2010.

[26] Q. Wang and M. Abubakar, "Human factors and their effects on human-centred assembly systems - A literature review-based study," in 2nd International Conference on Design and Manufacturing Engineering (ICDME2017), vol. 239. IOP Conf. Series: Materials Science and Engineering, 2017, 012006.

[27] M. Calzavara, D. Battini, D. Bogataj, F. Sgarbossa, and I. Zennaro, "Ageing workforce management in manufacturing systems: state of the art and future research," International Journal of Production Research, pp. 1-9, 2019

[28] A. Robertson and C. Tracy, "Health and productivity of older workers," Scand. J. Work Environ. Health, vol. 24 no. 2, pp. 85-97, 1998.

[29] V. Skirbekk, "Age and productivity capacity: Descriptions, causes and policy options," AGEING HORIZONS, vol. 8, pp. 4-12, 2008.

[30] J. llmarinen, "Aging workers," Occupational and environmental medicine, vol. 58, no. 8, pp. 546-552, 2001

[31] J. Bellew, B. Symons, and A. Vandervoort, "Geriatric fitness: effects of aging and recommendations for exercise in older adults," Cardiopulmonary Physical Therapy Journal (American Physical Therapy Association, Cardiopulmonary section), vol. 16, no. 1, pp. 20-31, 2005.

[32] M. Savinainen, "Physical capacity and workload among aging workers," Tempere: Medical school university of Tempere, 2004a.

[33] F. Boenzi, G. Mossa, G. Munmolo, and V. Romano, "Work aging in production systems: modelling and performance evaluation," in 25th DAAAM International Symposium on Intelligent Manufacturing and Automation. Bari, Italy: Elsevier, 2015, pp. 1108-1115.

[34] S. Hawkins and R. Wiswel, "Rate and mechanism of maximal oxygen consumption decline with aging implications for exercise training," Sports Medicine, vol. 33, no. 12 , pp. $877-888,2003$.

[35] D. Chaffin, Occupational Biomechanics, 4th ed. New Jersey: John Wiley, 2006.

[36] R. Ellis, E. Pines, and J. Allaire, "Performance implications of older workers in technological manufacturing environments: A task-analysis/human reliability perspective," International Journal of Computer Integrated Manufacturing, vol. 12, no. 2, pp. 104-112, 1999.

[37] R. Basu, A. Basu, and K. Nair, "Muscle changes in aging," The Journal of Nutrition, Health and Aging, vol. 6 , no. 5, pp. 336-341, 2002

[38] Y. Aoyagi and R. Shepherd, "Aging and muscle function," Sports Medicine, vol. 14, no. 6, pp. 376-396, 1992.

[39] B. Gall and W. Parkhouse, "Physical capacity as a function of age in heavy manual work," Ergonomics, vol. 47, no. 6 , pp. $671-687,2004$

[40] M. Savinainen, N. Clas-Håkan, O. Korhonen, and J. Ilmarinen, "Changes in physical capacity among middle- 
aged municipal employee over 16 years," Experimental Aging, vol. 30, no. 1, pp. 1-22, 2004b.

[41] J. Fleg, C. Morrell, A. Bos, L. Brant, L. Talbot, J. Wright, and E. Lakatta, "Accelerated longitudinal decline of aerobic capacity in healthy adults," Circulation, vol. 112 , no. 5 , pp. $674-682,2005$.

[42] H. Alaranta, H. Hurri, M. Hallovaara, A. Soukka, and R. Harju, "Flexibility of the spine: normative values of goniometric and tape measurement," Scandinavian Journal of Rehabilitation Medicine, vol. 26, no. 3, pp. 147-154, 1994

[43] S. Asogwa, A. Ibarra, N. Izmeron, M. Kumashiro, C. Ramachandra, J. Rantanen, and Z. Su, "Aging and working capacity," World Health Organisation, 1993, geneva.

[44] J. Ilmarinen, "Physical requirement associated with the work of aging workers in the european union," $E x$ perimental Aging Research, vol. 28, pp. 7-23, 2002.

[45] M. Anzanello and F. Fogliatto, "Learning curve models and applications: literature review and research directions," International Journal of Industrial Ergonomics, vol. 41 , pp. 573-583, 2002

[46] R. Costa and J. Lourenço, "Multi-response problems: desirability and other optimization," Journal of Chemometrics, vol. 30, pp. 702-714, 2016.

[47] N. Costa, J. Lourenço, and Z. Pereira, "Desirability function approach: A review and performance evaluation in adverse conditions," Chemometrics and Intelligent Laboratory Systems, vol. 107, pp. 234-244, 2011.

[48] A. Al-Zuheri, L. Luong, and K. Xing, "Prediction and analysis impact of operational design of a manual assembly system with walking workers on performance," International Journal of Computer Integrated Manufacturing, vol. 26, no. 6, pp. 540-560, 2013.

[49] F. Jr and J. Simpson, "A genetic algorithm with a modified desirability function approach to multiple response optimization," in IIE Annual Conference. Institute of Industrial and Systems Engineers (IISE), 2002.

[50] G. Derringer and R. Suich, "Simultaneous optimization of several response variables," Journal of quality technology, vol. 12, pp. 214-219, 1980. 